\title{
L'Incompréhensible. Littérature, réel, visuel. Sous la direction de Marie-Thérèse Mathet
}

\section{Luigi Luison}

\section{(2) OpenEdition}

1 Journals

\section{Edizione digitale}

URL: http://journals.openedition.org/studifrancesi/36993

DOI: 10.4000/studifrancesi.36993

ISSN: 2421-5856

\section{Editore}

Rosenberg \& Sellier

\section{Edizione cartacea}

Data di pubblicazione: 1 juillet 2005

Paginazione: 220-221

ISSN: 0039-2944

\section{Notizia bibliografica digitale}

Luigi Luison, «L'Incompréhensible. Littérature, réel, visuel. Sous la direction de Marie-Thérèse Mathet», Studi Francesi [Online], 145 (XLIX | I) | 2005, online dal 30 novembre 2015, consultato il 18 avril 2021 URL: http://journals.openedition.org/studifrancesi/36993 ; DOI: https://doi.org/10.4000/studifrancesi. 36993

Questo documento è stato generato automaticamente il 18 avril 2021.

\section{(c) $($ ) $\odot$ EY}

Studi Francesi è distribuita con Licenza Creative Commons Attribuzione - Non commerciale - Non opere derivate 4.0 Internazionale. 


\title{
L'Incompréhensible. Littérature, réel, visuel. Sous la direction de Marie- Thérèse Mathet
}

\author{
Luigi Luison
}

\section{NOTIZIA}

AV. VV., L'Incompréhensible. Littérature, réel, visuel. Sous la direction de Marie-Thérèse MATHET, Paris, L'Harmattan, 2003, pp. 413.

1 Questo volume è una raccolta di saggi che trattano dell'"incomprensibile" all'interno dell'opera letteraria. Pur consapevoli dell'aspetto paradossale del loro assunto, gli autori del testo hanno voluto mettere in discussione l'idea dell'incomprensibile come concetto negativo e privo di contenuto, e in quanto tale difficile da concettualizzare. L'inizio di una ricerca sul tema dell'incomprensibile nasce dal fatto che la letteratura possiede il privilegio di collocarsi oltre tale concetto. E proprio per questo può esplorarne il senso e fornire gli strumenti adeguati per approdare ad una riflessione teorica non sull'oggetto, ma suscitata dall'oggetto stesso.

Gli autori cristallizzano l'idea che, se da un punto di vista filosofico, l'incomprensibile si può distinguere dall"'inconcepibile" e dall' "inconoscibile", allora si può considerare come categoria a sè, all'interno della quale, però, ne sono racchiuse altre che occorre tenere in considerazione. I vari saggi analizzano questo concetto su più fronti; innanzitutto da un punto di vista narrativo, dove l'incomprensibile si differenzia dal "segreto", dall' "enigma" e dal "mistero"; in secondo luogo dal punto di vista diacronico, secondo cui l'incomprensibile si manifesta in maniera differente, a seconda dell'epoca presa in esame; ed infine, ma non ultimo, sul piano teorico, che considera l'incomprensibile una categoria capace di ostentare il reale.

3 La raccolta, suddivisa in tre grandi rubriche, si apre con una serie di saggi che hanno come tema centrale la "tragédie herméneutique". In questa sezione (pp. 29-168) sono 
stati raggruppati i lavori che tendono a considerare l'incomprensibile in sé. Rivelatrice, in tal senso, è l'analisi del Sonnet en Đxy di Mallarmé, la quale porta alla conclusione che l'apparente incomprensibile è un'illusione, poiché all'interno del testo non vi è nulla da comprendere. Proprio questo niente, invece, rappresenterebbe il componente principale dell'oggetto letterario. Di conseguenza, l'incomprensibile di Mallarmé rifletterebbe l'incomprensibile del reale. Ad avvalorare tale ipotesi sono stati presi in esame i personaggi flaubertiani di Bouvard e Pécuchet, che rappresentano l'illustrazione perfetta del fallimento ermeneutico dell'eroe.

4 La seconda sezione (Le cœur incompréhensible du récit, pp. 169-269) raccoglie studi che focalizzano la loro attenzione sul genere fantastico e sulla possibilità di verificare il legame tra fantastico ed incomprensibile. E un legame lo offrirebbero sia alcuni personaggi di Dostoïevski, sia alcuni personaggi creati da Proust; in effetti, egli ricorre a strategie narrative che fanno emergere l'incomprensibile dall'eccesso di informazioni provocate dalle scene più disparate $\mathrm{e}$ contraddittorie. In questo modo, l'incomprensibile, anziché dissolversi, aumenta sempre di più.

5 Il punto di vista diacronico introduce, infine, la terza parte di questo volume (De l'incompréhensible à la brutalité: le texte face au réel, pp. 273-405), che si concentra sul concetto di "brutalité" e sul suo posto nello spazio letterario. In questa prospettiva i lavori degli autori intendono dimostrare che è proprio con il XVIII secolo che il reale fa irruzione nella letteratura, diventando, al tempo stesso, un nuovo ambito epistemologico. Ne è un esempio l'ironia nell'opera volteriana, le cui dinamiche fanno passare per assurdo il discorso antico, affidando all'incomprensibile un ruolo di primaria importanza e nel contempo facendolo rimbalzare tra il simbolico ed il reale. 